\title{
IMPLANTAÇÃO DE UMA FERRAMENTARIA AUTÔNOMA NA MANUTENÇÃO INDUSTRIAL EM UMA INDÚSTRIA SUCROENERGÉTICA
}

\author{
Congresso Nacional Online de Empreendedorismo, 3a edição, de 06/12/2021 a 08/12/2021
} ISBN dos Anais: 978-65-81152-30-7

CeCilio; thaliane da SIlva ${ }^{1}$, PIOVeSAN; Gleice Copedê Piovesan 2, CHIME; Darlan Oliveira ${ }^{3}$, SILVA; Raniéri Alves da ${ }^{4}$, ROMAGNOLI; Jessica 5

\section{RESUMO}

Em um mundo onde a economia de tempo é amplamente discutida, o encurtamento dos processos é primordial para uma gestão inteligente. $O$ acompanhamento de todos os detalhes torna-se vital para o sucesso da gestão, principalmente quando o assunto é manutenção industrial. Assim, cada análise minuciosa é fundamental para que o desempenho seja o melhor possível. De acordo com a definição registrada pela Associação Brasileira de Normas Técnicas (ABNT), a manutenção industrial consiste em um conjunto de ações técnicas e administrativas que envolvem todo o ramo industrial. A crescente competitividade das indústrias exige que se procure constantemente a maior eficiência do sistema produtivo. Tendo isso em vista, este trabalho foi desenvolvido com o objetivo de implantar um sistema de ferramentaria industrial autônoma, justificado pela indisponibilidade de ferramentas, o alto custo gerado e o impacto nas manutenções industriais. O presente tema foi escolhido no intuito de buscar uma melhoria referente a indisponibilidade de ferramentas, com o objetivo de se obter uma economia bastante significativa, esperando-se obter menos quebras, desvios de ferramentas e diminuição no quadro de funcionários do setor, tendo relevância econômica. Em suma, melhorar a produtividade, manter confiabilidade nas ferramentas e reduzir custos foram razões pela qual foi escolhido o tema e desenvolvido o trabalho. A gestão de ferramentaria é a estratégia de controle, para maximizar a capacidade de utilização das ferramentas, garantindo a qualidade e confiabilidade dos serviços executados, reduzindo significativamente o tempo e custo de uso, de modo a alcançar maior produtividade. É importante destacar que o setor de manutenção industrial vem apostando em tecnologia e permitindo autonomia para que seus colaboradores exerçam suas funções de forma eficiente e segura. A metodologia empregada nessa pesquisa doi do tipo exploratória com abordagem quantitativa e os instrumentos de coletas de dados utilizados foram: entrevista presencial, questionários, observação direta, registros institucionais. Pretendeu-se com esta pesquisa desenvolver um projeto junto aos supervisores de manutenção industrial a implantação de uma ferramentaria autônoma. Para desenvolver esta pesquisa foram utilizados alguns recursos tecnológicos, como monitoramento por câmeras, acesso biométrico, sistema gerenciamento de ferramentas, e elaborado procedimentos de utilização padrão, para que o colaborador possa acessar o local sozinho, locar e devolver suas ferramentas de forma autônoma. Após aplicado treinamento e testes aos colaboradores, foi 
realizado a pesquisa de satisfação, que comprovam que os objetivos foram alcançados com uma média de $89 \%$ de relevância e aprovação ao novo modelo, que dá autonomia aos colaboradores ao locarem e devolverem suas ferramentas, visando diminuição de custo, aumento de disponibilidade e confiabilidade em ferramentas do local. Apenas 11\% responderam que a implantação da ferramentaria autônoma não foi útil e produtiva. Houve resistência por parteeguns colaboradores provavelmente devido a cultura organizacional. Mesmo assim a empresa vem tomando medidas para melhorar este cenário investindo em treinamento, dando mais autonomia aos colaboradores

PALAVRAS-CHAVE: Ferramentaria Autônoma, Manutenção Industrial, Confiabilidade 